\title{
Anxiety Levels and Clinical Decision-Making Skills of Nurses Providing Care for Patients Diagnosed with COVID-19
}

\author{
Cemile Savci $^{1 \star}$, Ayse Cil Akinci ${ }^{1,2}$, Furkan Keles $^{1}$
}

${ }^{1}$ Department of Nursing, Faculty of Health Sciences, Istanbul Medeniyet University, Istanbul, TURKEY

${ }^{2}$ School of Nursing, Loma Linda University, CA, USA

*Corresponding Author: cemile.savci@medeniyet.edu.tr

Citation: Savci C, Cil Akinci A, Keles F. Anxiety Levels and Clinical Decision-Making Skills of Nurses Providing Care for Patients Diagnosed with COVID-19. Electron J Gen Med. 2021;18(6):em322. https://doi.org/10.29333/ejgm/11300

\section{ARTICLE INFO}

Received: 8 Jul. 2021

Accepted: 26 Sep. 2021

\begin{abstract}
Introduction: Although there are studies evaluating the anxiety levels of nurses during COVID-19 pandemic, no study was found evaluating the clinical decision-making skills of nurses and the correlation between anxiety and clinical decision-making.
\end{abstract}

Objectives: In this study, the anxiety level experienced by nurses providing care for COVID-19 diagnosed patients during the pandemic, their clinical decision-making skills and the correlation between them were evaluated.

Methods: A descriptive and correlational study was completed with 150 nurses who were working in two pandemic hospitals in Istanbul between July and October 2020. The data were collected using Structured Questions Form, State-Trait Anxiety Inventory (STAI) and Clinical Decision Making in Nursing Scale (CDMNS). Data were analyzed using descriptive statistics and Pearson correlation analysis. Significance level was accepted as $\mathrm{p}<0.05$.

Results: STAI and CDMNS mean scores of the nurses were $50.59 \pm 10.20$ and $142.22 \pm 14.57$, respectively. There was no statistically significant correlation between the state anxiety level and clinical decision-making skills of the nurses participating in the study $(p>0.05)$. Nurses' age, educational level and professional experience duration had a positive and statistically significant correlation with CDMNS total scores $(p<0.05)$.

Conclusions: State anxiety levels and clinical decision-making skills of the nurses were high during COVID-19 pandemic and there was no correlation between anxiety level and clinical decision-making skills.

Keywords: anxiety, clinical decision-making, COVID-19, nursing

\section{INTRODUCTION}

COVID-19 infection has spread rapidly all over the world after the first case seen in Wuhan province in China in December 2019 and it was declared as a pandemic by the World Health Organization (WHO) on March 11, 2020 [1,2]. Epidemics of infectious diseases such as COVID-19 negatively affect both the physical health and psychological health of healthcare professionals $[3,4]$. In the studies, it has been reported that healthcare professionals experience psychological problems such as anxiety, stress disorder and depression during the COVID-19 pandemic $[5,6]$. It is stated that psychological problems experienced by healthcare professionals are often caused by contacting with infected people, lack of personal protective equipment, being isolated, adapting to a new work environment, feeling vulnerable, uncertainty of the process, having to protect the health of themselves, their families and other individuals, witnessing the loss of cared individuals/teammates, having children that need to be taken care of, concern of infecting family member, weak organizational support and being away from family and social support resources [7-11]. It is reported that nurses are at risk in terms of psychological distress and mental health problems since they meet the care needs of COVID-19 diagnosed patients [11] and even more anxiety is observed in nurses than physicians $[5,10]$.

As in COVID-19 pandemic period, nurses may have to make clinical decisions in a short time in versatile and complex environments in the healthcare system [11]. Clinical decision making, which is a part of the nursing process and adopted as a problem-solving approach by nurses [12], is a complex cognitive process involving the synthesis of information obtained through analysis, interpretation, explanation, inquiry, evaluation, communication, experience and observation. Clinical decision-making in nursing is very important in providing quality and safe care during nursing practices and improving the care outcomes of the patient/healthy individual $[13,14]$. Nurses' knowledge, clinical experience, individual characteristics (intuition, selfconfidence, healthy skepticism, etc.), complexity of the decision situation, and properties of the decision environment affect nurses to make correct and effective clinical decisions [15-17].

Nurses may have to make clinical decisions in a short time in multifaceted and complex environments, as in during the COVID-19 pandemic. The anxiety level experienced by the 
nurses during this process may negatively affect their clinical decision-making skills. While there are studies about the anxiety level of nurses during COVID-19 pandemic $[7,8,11,18$ 20], no study was found evaluating the clinical decision-making skills of nurses and the relationship between the clinical decision-making skills and the anxiety level of nurses. Therefore, in this study aimed to evaluate the anxiety and clinical decision-making skills of nurses providing care to COVID-19 diagnosed patients during the pandemic period and the correlation between them.

\section{METHODS}

\section{Study Design and Questions}

The design of this study is a descriptive and correlational. Research questions:

1. What is the anxiety level experienced by nurses providing care for patients diagnosed with COVID-19?

2. What is the clinical decision-making skills of nurses providing care for patients diagnosed with COVID-19?

3. Is there a correlation between anxiety level and clinical decision-making skills of nurses providing care for patients diagnosed with COVID-19?

\section{Sample}

The population of the study was composed of 307 nurses working in two pandemic hospitals in Istanbul province between July and October 2020. 150 nurses who were over the age of 18 years, working as a nurse in a pandemic hospital, providing care to a patient diagnosed with COVID-19, were not off or sick within the dates when the study would be conducted, agreed to participate were included in the study with the sampling error of 0.05 .

\section{Data Collection Tools}

Data were collected using the "Structured Questions Form", "State-Trait Anxiety Inventory (STAI)", and "Clinical Decision Making in Nursing Scale (CDMNS)".

Structured Questions Form prepared by the researchers in accordance with the literature [11,18,20-23]. There are 5 questions about determining descriptive characteristics of the nurses such as age, gender, marital status, education status, and professional experience duration, in the first section of the structured questions form consisting of two sections. The second part is composed of 11 questions for determining the effect of COVID-19 pandemic on the nurses' working style, lifestyle, mood, patient care, and emotions they experience during patient care.

State-Trait Anxiety Inventory (STAI) a self-report questionnaire consisting of short statements developed by Spielberger, Gorsuch and Lushene [24] to determine the state anxiety level. It was adapted to Turkish by Öner and Le Compte [25]. STAI is composed of a total of 20 items requiring the individual to describe how he/she feels at a certain moment and specific conditions and to respond by considering their emotions about the conditions he/she is in. In the four-point Likert type inventory, each item is scored between 1-4 points. There are 10 reversed items in the inventory. The total score of the inventory varies between 20 and 80 . In the assessment, it is interpreted that 0-19 points refer to "no anxiety", 20-39 points refer to "mild anxiety", 40-59 points refer to "moderate anxiety", 60-79 points refer to "severe anxiety", and 80 points refer to "panic value" $[25,26]$. The Cronbach's alpha internal consistency coefficient of the inventory adapted to Turkish is 0.94 [25]. It is 0.91 in this study.

Clinical Decision Making in Nursing Scale (CDMNS) developed by Jenkins [27] for nursing students in the USA, defines the clinical decision-making levels of the students based on their own statements [28]. CDMNS is composed of 40 items and four sub-scales. The subscales of the scale are "Search for alternatives or options", "Canvassing of objectives and values", "Evaluation and reevaluation of consequences", and "Search for information and unbiased assimilation of new information". Each subscale is composed of 10 items. The overall scale of four-point Likert type is scored between 40 and 200 and each subscale is scored between 10 and 50 points and there is no cut-off point. High score from the scale indicates high decision-making skill and low score refers to low decisionmaking skill. Assessment of the scale is made over each subscale and the scale total score $[28,29]$. The Cronbach's alpha internal consistency coefficient of the original scale is 0.83 [27]. It is 0.78 in the Turkish adaptation made by Edeer and Sarıkaya [29]. It is 0.82 in this study.

\section{Data Collection}

The data of the study were collected after obtaining the approval of ethics committee. Participants filled out the data collection form on Google Forms link shared via e-mail.

\section{Ethical Considerations}

This study was conducted in accordance with the principles stated in the Declaration of Helsinki. In order to implement the study, ethics committee approval was obtained (01.07.2020/121). Before data collection, the participants were informed about the subject of the study, and their consent to participate in the study was obtained through an electronic survey.

\section{Statistical Analysis}

The data was analyzed with SPPS 22 (Statistical Package for the Social Science for Windows, Version 22.0) statistical package program. For the categorical and continuous variables, number, percentage, mean, standard deviation, minimum and maximum values from descriptive statistics were calculated. Kolmogorov-Smirnov test was used in determining the compatibility of the data to normal distribution. Pearson correlation coefficient was used to investigate the correlation between two quantitative variables having normal distribution. Significance level was accepted as $p<0.05$.

\section{RESULTS}

\section{Characteristics of the Nurses}

It was found that of 150 nurses, who had a mean age of $33.82 \pm 8.75$ years, $83.3 \%$ were female, $56.7 \%$ were married, and $60 \%$ had a bachelor's degree. It was determined that the nurses had a professional experience duration of $11.90 \pm 9.46$ years in average, clinics of $64.7 \%$ of them changed due to the pandemic, $56.7 \%$ were working in shifts and $45.4 \%$ changed their working style due to the pandemic, $64.7 \%$ were not satisfied with the changed working and style, most of them received training on the care of patients diagnosed with COVID- 
Table 1. Characteristics of the nurses $(n=150)$

\begin{tabular}{|c|c|c|}
\hline Variables & Mean \pm SD & Min-Max \\
\hline Age (years) & $33.82 \pm 8.75$ & $20-56$ \\
\hline Professional experience duration (years) & $11.90 \pm 9.46$ & $1-33$ \\
\hline Variables & $\mathbf{n}$ & $\%$ \\
\hline \multicolumn{3}{|l|}{ Gender } \\
\hline Male & 25 & 16.7 \\
\hline Female & 125 & 83.3 \\
\hline \multicolumn{3}{|l|}{ Marital status } \\
\hline Married & 85 & 56.7 \\
\hline Single & 65 & 43.3 \\
\hline \multicolumn{3}{|l|}{ Educational level } \\
\hline High school & 6 & 4.0 \\
\hline Associate degree & 15 & 10.0 \\
\hline Bachelor's degree & 90 & 60.0 \\
\hline Master's degree & 39 & 26.0 \\
\hline \multicolumn{3}{|l|}{ Change of the clinic due to the pandemic } \\
\hline Yes & 53 & 35.3 \\
\hline No & 97 & 64.7 \\
\hline \multicolumn{3}{|l|}{ Working style } \\
\hline Shift & 85 & 56.7 \\
\hline Steady daytime & 53 & 35.3 \\
\hline Night constantly & 12 & 8.0 \\
\hline \multicolumn{3}{|l|}{ Change of working style due to the pandemic } \\
\hline Yes & 68 & 45.4 \\
\hline No & 82 & 54.6 \\
\hline \multicolumn{3}{|l|}{ Satisfaction with the new working style } \\
\hline Yes & 24 & 35.3 \\
\hline No & 44 & 64.7 \\
\hline \multicolumn{3}{|c|}{$\begin{array}{l}\text { Training status for the care of the patient diagnosed with COVID- } \\
19\end{array}$} \\
\hline Yes & 94 & 62.7 \\
\hline No & 56 & 37.3 \\
\hline \multicolumn{3}{|c|}{ Training status for the use of isolation and protective equipment } \\
\hline Yes & 109 & 72.7 \\
\hline No & 41 & 27.3 \\
\hline
\end{tabular}

$19(62.7 \%)$, the use of isolation and protective equipment (72.7\%) (Table 1).

\section{Feelings and Experiences In-patient Care of the Nurses}

It was seen that the majority of the participants felt anxious $(69.3 \%)$ and stressful (60\%) while providing care to a patient diagnosed with COVID-19. Anxiety (58\%) and stress (50.7\%) feelings took place near the top although they decreased during the next care giving. Almost all of the participants $(96.7 \%)$ did not receive psychological support during the COVID-19 pandemic (Table 2).

It was determined that $52 \%$ of the participants had difficulties about the patient care. These experienced difficulties were working by using personal protective equipment (sweating due to the equipment, preventing to move freely, etc.) (50.7\%) and having difficulties in communicating with the team and patients due to personal protective equipment (Table 2).

\section{Distribution of the STAI and CDMNS Mean Scores of the Nurses}

STAI mean score of the nurses was $50.59 \pm 10.20$. Nurses' mean scores of the "Search for alternatives or options", "Canvassing of objectives and values", "Evaluation and reevaluation of consequences", and "Search for information and unbiased assimilation of new information" subscales of CDMNS were $37.64 \pm 4.46, \quad 35.98 \pm 5.18,34.34 \pm 3.45$, and
Table 2. Feelings and experiences in-patient care of the nurses during pandemic

\begin{tabular}{lcc}
\hline Variables & $\mathbf{n}$ & $\%$ \\
\hline $\begin{array}{l}\text { How do you feel while providing the first care to the patient } \\
\text { diagnosed with COVID-19* }\end{array}$ & & \\
\hline I didn't feel any difference & 9 & 6.0 \\
\hline Anxiety & 104 & 69.3 \\
\hline Stress & 90 & 60.0 \\
\hline Fear & 85 & 56.7 \\
\hline Sadness & 38 & 25.3 \\
\hline
\end{tabular}

How do you feel in the steps after the first care to the patient diagnosed with COVID-19*

\begin{tabular}{lcc}
\hline I didn't feel any difference & 33 & 22.0 \\
\hline Anxiety & 87 & 58.0 \\
\hline Stress & 76 & 50.7 \\
\hline Sadness & 68 & 45.3 \\
\hline Fear & 55 & 36.7 \\
\hline Status of receiving psychological support & & \\
\hline Yes & 5 & 3.3 \\
\hline No & 145 & 96.7 \\
\hline Sta
\end{tabular}

\begin{tabular}{ccc}
\hline Status of having difficulty in patient care & & \\
\hline Yes & 78 & 52.0 \\
\hline No & 72 & 48.0
\end{tabular}

\section{Difficulties experienced during patient care*}

Working with personal protective equipment

(sweating due to equipment, preventing movement, $76 \quad 50.7$ etc.)

Difficulty in communicating with the team and $59 \quad 39.3$

patients due to personal protective equipment

Difficulty due to the constant cleaning of tools such

as stethoscope, phone, keyboard during the shift due $\quad \begin{array}{ll}48 & 32.0\end{array}$ to the risk of infection

$\begin{array}{lll}\text { Difficulty in treatment practices due to the infection } & 32 & 21.3\end{array}$ risk

Difficulty in practices for respiratory activity (oxygen

therapy, nebulization, aspiration, etc.) due to the $27 \quad 18.0$ infection risk.

Difficulty in monitoring vital signs due to infection $26 \quad 17.3$ risk

\begin{tabular}{lll} 
Answering the phone calls of patients' relatives & 24 & 16.0 \\
\hline
\end{tabular}

Difficulty in positioning the patient because of the $15 \quad 10.0$ concern of infection risk

${ }^{*}$ Multiple answers were given

$34.26 \pm 4.04$, respectively. CDMNS mean score of the nurses was 142.22 \pm 14.57 (Table 3).

The Correlation between Nurses' Clinical Decision-making Skills and Anxiety Levels, Age, Educational Level and Professional Experience Duration

There was no statistically significant correlation between the state anxiety level and clinical decision-making skills of the nurses participating in the study. The nurses' age and professional experience duration had no statistically significant correlation with their STAI total mean scores $(p>0.05)$. Nurses' age and professional experience duration had a positive and statistically significant correlation with "Search for alternatives or options" and "Evaluation and reevaluation of consequences" subscales and CDMNS total mean scores $(p<0.05)$. Nurses' educational level had a positive and statistically significant correlation with all subscales and CDMNS total mean scores $(p<0.05)$. As the nurses' age, educational level and professional experience duration increased, their clinical decision-making skills in nursing also increased $(p<0.05)$ (Table 4). 
Table 3. STAI and CDMNS mean scores of the nurses $(n=150)$

\begin{tabular}{|c|c|c|c|}
\hline & Min & Max & Mean \pm SD \\
\hline \multicolumn{4}{|l|}{ STAI } \\
\hline Total & 20.00 & 75.00 & $50.59 \pm 10.20$ \\
\hline \multicolumn{4}{|l|}{ CDMNS } \\
\hline Search for alternatives or options & 26.00 & 49.00 & $37.64 \pm 4.46$ \\
\hline Canvassing of objectives and values & 27.00 & 45.00 & $34.34 \pm 3.45$ \\
\hline Evaluation and reevaluation of consequences & 25.00 & 48.00 & $35.98 \pm 5.18$ \\
\hline Search for information and unbiased assimilation of new information & 27.00 & 44.00 & $34.26 \pm 4.04$ \\
\hline Total & 115.00 & 178.00 & $142.22 \pm 14.57$ \\
\hline
\end{tabular}

STAI: State-Trait Anxiety Inventory, CDMNS: Clinical Decision Making in Nursing Scale

Table 4. The correlation between age, educational level, professional experience duration, STAI and CDMNS mean scores of the nurses $(n=150)$

\begin{tabular}{|c|c|c|c|c|c|c|c|}
\hline & & \multirow[b]{2}{*}{ STAI } & \multicolumn{5}{|c|}{ Clinical Decision Making in Nursing Scale } \\
\hline & & & $\begin{array}{c}\text { Search for } \\
\text { alternatives or } \\
\text { options }\end{array}$ & $\begin{array}{c}\text { Canvassing of } \\
\text { objectives and values }\end{array}$ & $\begin{array}{l}\text { Evaluation and } \\
\text { reevaluation of } \\
\text { consequences }\end{array}$ & $\begin{array}{c}\text { Search for information and } \\
\text { unbiased assimilation of } \\
\text { new information }\end{array}$ & Total \\
\hline \multirow{2}{*}{ STAI } & $r$ & - & 0.040 & 0.041 & 0.018 & -0.159 & -0.016 \\
\hline & $\mathrm{p}$ & - & 0.626 & 0.618 & 0.828 & 0.052 & 0.849 \\
\hline \multirow{2}{*}{ Age } & $r$ & 0044 & $0.198^{\star}$ & 0.087 & $0.194^{\star}$ & 0.087 & $0.174^{*}$ \\
\hline & $p$ & 0.594 & 0.015 & 0.291 & 0.017 & 0.287 & 0.033 \\
\hline \multirow{2}{*}{ Educational level } & $r$ & -0.083 & $0.310^{\star \star}$ & $0.208^{\star}$ & $0.323^{\star \star}$ & $0.364^{\star *}$ & $0.360^{*}$ \\
\hline & $\mathrm{p}$ & 0.311 & 0.000 & 0.011 & 0.000 & 0.000 & 0.000 \\
\hline \multirow{2}{*}{$\begin{array}{c}\text { Professional } \\
\text { experience duration }\end{array}$} & $r$ & 0.042 & $0.194^{*}$ & 0.109 & $0.187^{\star}$ & 0.063 & $0.169^{*}$ \\
\hline & $\mathrm{p}$ & 0.609 & 0.017 & 0.186 & 0.022 & 0.444 & 0.039 \\
\hline
\end{tabular}

\section{DISCUSSION}

COVID-19 infection constitutes a great threat to human life and health due to its high transmission rate and fatality in severe cases $[1,30]$. Healthcare professionals are always at the forefront of the pandemic and risking their lives to fulfill their duties [30]. It was reported in previous studies that Severe Acute Respiratory Syndrome (SARS) caused great pain to healthcare professionals and caused much more pain in nurses than physicians. This is because nurses are in close contact with patients for a long time as the nature of their profession [31].

It was determined that the majority of the nurses felt anxious (69.3\%) and stressed (60\%) during the first care of patients diagnosed with COVID-19, feelings of anxiety (58\%) and stress $(50.7 \%)$ decreased but continued during the next care. In addition, STAI mean score $(50.59 \pm 10.20)$ of the nurses was higher than normal. Similar to results of the present study, it was determined that most of the healthcare professionals felt anxious and moderately stressed during COVID-19 pandemic [32], STAI mean scores of the nurses were 51.51 \pm 9.94 [8] and 57.0 55.64 [19]. Protecting the mental health of the nurses who constitute the backbone of the healthcare system in the delivery of healthcare services is very valuable in managing the process more effectively. Therefore, it is important to determine and implement appropriate and effective strategies for the protection of mental health of nurses [33]. However, it was determined in this study that almost all of the nurses $(96.7 \%)$ did not receive any psychological support during the COVID-19 pandemic. Zhan et al. [34], stated in their study that almost $90 \%$ of the nurses did not receive professional psychological support. Supporting especially nurses with high levels of anxiety and stress psychologically is important for the protection of their short and long-term health. For this purpose, mobile mental health support systems (RUHSAD application, mental support line for healthcare professionals etc.) has been implemented especially by the Ministry of Health as well as many other organizations and associations. Since the number of nurses receiving psychological support is less in this study, it is also crucial to raise nurses' awareness about receiving psychological support and to establish in-house individual and group support systems.

The pandemic process requires nurses to be more creative for new solutions and to make fast and difficult decisions in care environments. In this study, the clinical decision-making skills of the participants were higher than normal. In addition, there was no statistically significant correlation between the nurses' state anxiety level and clinical decision-making status. One of the primary duties and independent roles of a nurse is patient care. The nurse performs this role in accordance with the contemporary nursing philosophy with an individualcentered, humanistic and holistic approach, using his/her scientific knowledge and decision-making skill through the nursing process. High clinical decision-making skills of the nurses during COVID-19 pandemic has showed that nurses searches for information, inquire about goals and values, investigate options and ideas and evaluate results even under difficult conditions. High clinical decision-making skill despite the anxiety level higher than normal was considered as reflection of professionalization and autonomy in nursing.

The nurses' age, educational level and professional experience duration had a positive and statistically significant correlation with CDMNS total score and "Search for alternatives or options", "Evaluation and reevaluation of consequences" subscale mean scores. Although there are different research results, it has often been reported that age, knowledge, experience, education and environmental factors positively affect the clinical decision making $[23,35]$. Although it is not a factor affecting clinical decision-making alone, education is stated to develop situational awareness in professional settings and facilitate patient management [36]. 
In the study by Park and Kwon [16], clinical decision making scores of nurses with undergraduate and graduate degree were found to be high. It is stated in the literature that the time spent as a nurse increases self-confidence and facilitates decisionmaking. It is also emphasized that professional experience may affect autonomous decision making in nursing practices [36]. In the study by Park and Kwon [16], clinical decision-making scores of nurses with more than five years of clinical experiences were found to be high. In conclusion, it was determined that increasing age and professional experiences of nurses positively affected the clinical decision-making even during the pandemic.

\section{Limitation and Strengths of the Study}

The obtained data belong to the nurses, who were working in two pandemic hospitals and agreed to participate in the study, and cannot be generalized to all nurses in the pandemic process. No study was found in the current literature on the evaluating the correlation between the anxiety levels experienced by nurses and their clinical decision-making skills during COVID-19 pandemic. It is recommended to conduct similar studies with larger samples on this subject in the future.

\section{CONCLUSION}

In conclusion, nurses felt anxious and stressed during the first care of patients diagnosed with COVID-19 and their feelings of anxiety and stress decreased but continued during the next care. State anxiety levels and clinical decision-making skills of the nurses were higher than normal. Also, very few nurses applied to psychological support during this period. There was no statistically significant correlation between anxiety level and clinical decision-making skills. The nurses' age, educational level and professional experience duration had a positive and statistically significant correlation with CDMNS total score.

It is recommended to protect and promote the nurses' health, conduct interventions toward psychological self-care (developing skills about anxiety and stress management, receiving professional mental health support, etc.), professional self-care (improving working conditions, organizing regular meetings with colleagues to discuss important cases, getting support from a more senior colleague or clinician for difficult situations, etc.).

Author contributions: Conception and design: CS, ACA, FK Acquisition of data: CS, FK; Analysis: CS, ACA, FK; Interpretation of data: CS, ACA, FK; Been involved in drafting the manuscript or revising it critically for important intellectual content: CS, ACA. All authors have sufficiently contributed to the study, and agreed with the results and conclusions.

Funding: The authors declared that this study has received no financial support.

Acknowledgements: The authors would like to thank the al participating in this study.

Declaration of interest: The authors have no conflict of interest to disclose.

Ethics committee approval: Ethics committee approval was received for this study from the Istanbul Gaziosmanpasa Training and Research Hospital Clinical Research Ethics Committee (approval date/registration number: 01.07.2020/121).

\section{REFERENCES}

1. Huang C, Wang Y, Li X, Ren L, Zhao J, Hu Y, et al. (2020a). Clinical features of patients infected with 2019 novel coronavirus in Wuhan, China. The Lancet. 2020a; 395(10223):497-506. https://doi.org/10.1016/S22132600(20)30079-5

2. World Health Organization (2020). WHO Announces COVID19 Outbreak a Pandemic. Available at: https://www.euro. who.int/en/health-topics/health-emergencies/corona virus-covid-19/news/news/2020/3/who-announces-covid19-outbreak-a-pandemic

3. Chew NW, Lee GK, Tan BY, Jing M, Goh Y, Ngiam NJ, et al. A multinational, multicentre study on the psychological outcomes and associated physical symptoms amongst healthcare workers during COVID-19 outbreak. Brain, Behavior, and Immunity. 2020;88:559-65. https://doi.org/10.1016/j.bbi.2020.04.049 PMid:32330593 PMCid:PMC7172854

4. McAlonan GM, Lee AM, Cheung V, Cheung C, Tsang KW, Sham PC, et al. Immediate and sustained psychological impact of an emerging infectious disease outbreak on health care workers. Can J. Psychiat. 2007;52(4):241-7. https://doi.org/10.1177/070674370705200406 PMid:17500305

5. Huang JZ, Han MF, Luo TD, Ren AK, Zhou XP. Mental health survey of 230 medical staff in a tertiary infectious disease hospital for COVID-19. Zhonghua. 2020b;38(3):192-5. https://doi.org/10.3760/cma.j.cn121094-20200219-00063

6. Shaukat N, Ali DM, Razzak J. Physical and mental health impacts of COVID-19 on healthcare workers: a scoping review. Shaukat et al. International Journal of Emergency Medicine. 2020;13:40. https://doi.org/10.1186/s12245-02000299-5 PMid:32689925 PMCid:PMC7370263

7. Aktura SC, Ozden G. Salginin psikolojik etkileri: COVID-19 hemsireleri (Psychological effects of the epidemic: nurses of COVID-19). Uluslararasi Sosyal Arastirmalar Dergisi. 2020;13(73):1146-51. https://doi.org/10.17719/jisr.11049

8. Bahadir-Yilmaz E, Yuksel A. State anxiety levels of nurses providing care to patients with COVID-19 in Turkey. Perspectives in Psychiatric Care. 2020; 1-7. https://doi.org/10.1111/ppc.12661 PMid:33103790

9. Jiang Y. Psychological impact and coping strategies of frontline medical staff in Hunan between January and March 2020 during the outbreak of Coronavirus Disease 2019 (COVID-19) in Hubei, China. Med Sci Monit. 2020; 26:e924171. https://doi.org/10.12659/MSM.924171

10. Labrague LJ, De los Santos JAA. COVID - 19 anxiety among front - line nurses: Predictive role of organisational support, personal resilience and social support. Journal of Nursing Management. 2020;28(7):1653-61. https://doi.org/ 10.1111/jonm.13121 PMid:32770780 PMCid:PMC7436313

11. Maben J, Bridges J. Covid - 19: Supporting nurses' psychological and mental health. Journal of Clinical Nursing. 2020;29:2742-50. https://doi.org/10.1111/jocn. 15307 PMid:32320509 PMCid:PMC7264545

12. Dicle A, Edeer AD. Examination of clinical decision making perceptions of nursing students. The New Educational Review. 2013;33(3):134-44.

13. Chen SL, Hsu HY, Chang CF, Lin EC. An exploration of the correlates of nurse practitioners' clinical decision-making abilities. Journal of Clinical Nursing. 2016;25(7-8):1016-24. https://doi.org/10.1111/jocn.13136 PMid:26879045 
14. Johansen ML, O'Brien JL. Decision making in nursing practice: a concept analysis. Nursing Forum. 2016;51(1):408. https://doi.org/10.1111/nuf.12119 PMid:25639525

15. Botti M, Reeve R. Role of knowledge and ability in student nurses' clinical decision-making. Nursing and Health Sciences. 2003;5(1):39-49. https://doi.org/10.1046/j.14422018.2003.00133.x PMid:12603720

16. Park S, Kwon IG. Factors influencing nurses' clinical decision making-focusing on critical thinking disposition. Taehan Kanho Hakhoe Chi. 2007;37(6):863-71. https://doi.org/10.4040/jkan.2007.37.6.863 PMid:17992058

17. Sucu G, Dicle A, Saka O. Hemsirelikte klinik karar verme, etkileyen etmenler ve karar verme modelleri. Hemsirelikte Egitim ve Arastirma Dergisi. 2012;9(1):52-60.

18. Huang L, Lei W, Xu F, Liu H, Yu L. Emotional responses and coping strategies in nurses and nursing students during COVID-19 outbreak: A comparative study. PLOS ONE. 2020; 15(8): e0237303. https://doi.org/10.1371/journal.pone. 0237303 PMid:32764825 PMCid:PMC7413410

19. Saricam M. COVID-19-Related anxiety in nurses working on front lines in Turkey. Nursing and Midwifery Studies. 2020; 9(3):178-81. https://doi.org/10.4103/nms.nms_40_20

20. Tu ZH, He JW, Zhou N. Sleep quality and mood symptoms in conscripted frontline nurse in Wuhan, China during COVID-19 outbreak: a cross-sectional study. Medicine. 2020;99(26):1-5. https://doi.org/10.1097/MD.00000000000 20769 PMid:32590755 PMCid:PMC7328950

21. James $A H$, Bennett $C L$. Effective nurse leadership in times of crisis. Nursing Management. 2020;27(4):32-40. https://doi.org/10.7748/nm.2020.e1936

22. Korkmaz S, Kazgan A, Cekic S, Tartar AS, Balci HN, Atmaca $M$. The anxiety levels, quality of sleep and life and problemsolving skills in healthcare workers employed in COVID-19 services. Journal of Clinical Neuroscience. 2020;80:131-6. https://doi.org/10.1016/j.jocn.2020.07.073 PMid:33099335 PMCid:PMC7425768

23. Wu M, Yang J, Liu L, Ye B. An investigation of factors influencing nurses' clinical decision-making skills. Western Journal of Nursing Research. 2016;38(8):974-91. https://doi.org/10.1177/0193945916633458 PMid:26906246

24. Spielberger CD, Gorsuch RL, Lushene RE. Manual for the State-Trait Anxiety Inventory (Self Evaluation Questionnaire). Palo Alto California: Consulting Psychologist. 1970;22:1-24.

25. Oner N, Le Compte A. Sureksiz durumluk/surekli kaygi envanteri el kitabi. Istanbul: Bogazici Universitesi Yayinevi; 1998.

26. Oner N. Turkiye'de kullanilan psikolojik testlerden ornekler. Istanbul: Bogazici Universitesi Yayinevi; 2006.
27. Jenkins $H$. Perceptions of decision making among baccalaureate nursing students as measured by the clinical decision making in nursing scale. Doctors of Thesess, University of Maryland; 1983.

28. Jenkins HM. Clinical decision making in nursing scale. Measurement of Nursing Outcomes. 2001;1:33-40.

29. Edeer AD, Sarikaya A. Adaptation of clinical decision making in nursing scale to undergraduate students of nursing: the study of reliability and validity. International Journal of Psychology and Educational Studies. 2015;2(3):1-9. https://doi.org/10.17220/ijpes.2015.03.001

30. Gao J, Zheng P, Jia Y, Chen H, Mao Y, Chen S, et al. Mental health problems and social media exposure during COVID19 outbreak. PLOS ONE. 2020;15(4):e0231924. https://doi.org/10.1371/journal.pone.0231924 PMid:32298385 PMCid:PMC7162477

31. Wong TW, Yau JK, Chan CL, Kwong RS, Ho SM, Lau CC, et al. The psychological impact of severe acute respiratory syndrome outbreak on healthcare workers in emergency departments and how they cope. Eur J Emerg Med. 2005;12(1):13-8. https://doi.org/10.1097/00063110200502000-00005 PMid:15674079

32. Du J, Dong L, Wang T, Yuan C, Fu R, Zhang L, et al. Psychological symptoms among frontline healthcare workers during COVID-19 outbreak in Wuhan. General Hospital Psychiatry. 2020;67:144-5. https://doi.org/10.1016 /j.genhosppsych.2020.03.011 PMid:32381270 PMCid: PMC7194721

33. Ehrlich H, McKenney M, Elkbuli A. Protecting our healthcare workers during the COVID-19 pandemic. Am J Emerg Med. 2020;38(7):1527-8. https://doi.org/10.1016/j.ajem.2020.04. 024 PMid:32336585 PMCid:PMC7162741

34. Zhan Y, Liu Y, Liu H, Li M, Shen Y, Gui L, et al. Factors associated with insomnia among Chinese front - line nurses fighting against COVID - 19 in Wuhan: A cross sectional survey. Journal of Nursing Management. 2020;28(7):1525-35. https://doi.org/10.1111/jonm.13094 PMid:32657449 PMCid:PMC7405094

35. Hoffman K, Donoghue J, Duffield C. Decision - making in clinical nursing: investigating contributing factors. Journal of Advanced Nursing. 2004;45(1):53-62. https://doi.org/ 10.1046/j.1365-2648.2003.02860.x PMid:14675301

36. Nibbelink CW, Brewer BB. Decision - making in nursing practice: An integrative literatüre review. Journal of Clinical Nursing. 2018;27(5-6):917-28. https://doi.org/10.1111/ jocn.14151 PMid:29098746 PMCid:PMC5867219 